\title{
Karyotype characterization of two populations of Vernonia geminata (Asteraceae, Vernonieae) using banding and FISH techniques
}

\author{
V.M. Oliveira ${ }^{1}$, M.E. Mansanares ${ }^{2}$, J. Semir ${ }^{1}$ and E.R. Forni-Martins ${ }^{1}$ \\ ${ }^{1}$ Laboratório de Biossistemática e Evolução, \\ Departamento de Biologia Vegetal, Instituto de Biologia, \\ Universidade Estadual de Campinas, Campinas, SP, Brasil \\ ${ }^{2}$ Setor de Botânica, Departamento de Biologia, \\ Universidade Federal de Lavras, Lavras, MG, Brasil \\ Corresponding author: E.R. Forni-Martins \\ E-mail: elianafm@unicamp.br
}

Genet. Mol. Res. 11 (4): 4204-4212 (2012)

Received October 20, 2011

Accepted June 5, 2012

Published September 25, 2012

DOI http://dx.doi.org/10.4238/2012.September.25.1

\begin{abstract}
In order to extend our knowledge concerning karyotypes of the genus Vernonia, we applied various techniques of chromosome banding, including AgNOR and triple staining with the fluorochromes CMA/DA/DAPI (CDD), and of fluorescent in situ hybridization (FISH) for the $45 \mathrm{~S}$ rDNA probe to specimens of two populations of Vernonia geminata collected from an open-pasture area, in southern Brazil. B chromosomes were observed in one of the populations. Both populations of $V$. geminata presented a pair of $\mathrm{CMA}_{3}{ }^{+}$terminal bands and one pair of chromosomes with terminal AgNOR banding. The FISH evidenced, in one population, two pairs of small sites of $45 \mathrm{~S}$ rDNA; these being two small terminal sites and two centromeric sites. In the other population, there was only one pair of small terminal sites and two sites in two B chromosomes, one in each chromosome. There was coincidence of localization between $\mathrm{CMA}^{+}$and NOR bands with one of the small terminal sites
\end{abstract}


of $45 \mathrm{~S}$ rDNA of one chromosome of the normal complement, but not in $\mathrm{B}$ chromosomes.

Key words: AgNOR banding; CMA banding; Physical mapping; $45 \mathrm{~S}$ rDNA site

\section{INTRODUCTION}

Vernonia Schreb. (Asteraceae, Vernonieae) comprises small herbs to large trees (Stutts, 1988), occurring in tropical regions of Asia, Africa and Americas (Dematteis, 1998). It is one of the most complex genera of the family (Dematteis and Fernández, 1998), with more than 1000 species (Robinson, 1999). Recently, Robinson (1999) proposed that the traditional genera of Vernonieae must be regrouped, but their modifications were not accepted by most workers in this field. Studies involving genera of this tribe elaborated by Robinson (1999) resulted in the splitting of the genus Vernonia into 22 genera.

Vernonia geminata Kunth., which according to Robinson (1999) now belongs to the genus Lepidaploa (Cass.) Cass., occurs from Mexico to South America (Jorgensen and Ulloa, 1994), including the "cerrado" (Oliveira et al., 2007a) and disturbed areas in Brazil. It is an important honey species, where its pollen is detected in the honey and the larval food of Tetragonisca angustula Latreille, a bee species found in Chiapas, Mexico (Martínez-Hernández et al., 1994). Karyotypes of $V$. geminata and other species of Vernonia have been described by Oliveira et al. (2007a) by conventional staining. $V$. geminata has $2 \mathrm{n}=20$ chromosomes predominantly metacentric, varying from 2.0 to $4.6 \mu \mathrm{m}$. Oliveira et al. (2007a) reported the occurrence of B chromosomes (0-6) in one population of this species.

Karyotype analysis is essential for the cytogenetic characterization of species and to examine the variation between its individuals and/or populations (Guerra, 1988). The comparison of karyotypes of different species also allows the taxonomic and evolutionary analysis of a taxon, such as a genus. Many times, differences in karyotype asymmetry can indicate how these chromosomes have diversified in size and morphology within a group (Guerra, 1988).

Chromosome numbers of only $20 \%$ of Vernonia have been reported, varying from $2 \mathrm{n}=18$ to 160 (Oliveira et al., 2007a). The karyotypes determined with conventional techniques include only 5\% of the species of Vernonia, and they do not discriminate very well species with the same chromosome number, due to small variation in chromosome size and centromeric position (Ruas et al., 1991; Dematteis, 1996, 1998; Dematteis and Fernández, 1998, 2000; Oliveira et al., 2007a,b). To date, information obtained by techniques that allow the linear differentiation of the chromosomes [chromosome banding and fluorescent in situ hybridization (FISH)] exists for only one species, Vernonia condensata Baker $(2 n=40)$. Fluorochrome staining with chromomycin $\mathrm{A}_{3}$ /4',6-diamidino-2-phenylindole dihydrochloride $\left(\mathrm{CMA}_{3} / \mathrm{DAPI}\right)$ has revealed five chromosome pairs bearing subterminal $\mathrm{CMA}^{+} / \mathrm{DAPI}^{-}$heterochromatin (Salles-de-Melo et al., 2010).

Among banding techniques, staining with some fluorochromes determines the composition of bases of the heterochromatin (Schweizer, 1976). The fluorochrome DAPI preferentially stains AT-rich DNA, while $\mathrm{CMA}_{3}$ preferentially stains GC-rich DNA. Guerra et al. (2000), in studying the pattern of heterochromatic bands in Rutaceae, subfamily Aurantioideae, observed that the genus most basal in the group showed smaller amounts of heterochro- 
matin than did the more derived genera. Beyond fluorochrome banding, specific staining with silver nitrate or AgNOR can be used (Goodpasture and Bloom, 1975) to identify the nucleolus and chromosomes that have nucleolus organizer regions (NOR) that had been active in interphase. Using AgNOR staining, Moscone et al. (1995) showed possible trends in the karyotypic evolution of Capsicum L. (Solanaceae) with $\mathrm{x}=12$ chromosomes, and they proposed that the presence of bands, located in the first pair of metacentric chromosomes and in the 12th pair of subtelocentric chromosomes, is an ancestral condition for species belonging to the basal sub-group (A).

FISH is a good method to locate specific sites of nucleic acid (DNA or RNA) in the cytoplasm, organelles, chromosomes, or nucleus of biological material (Leitch et al., 1994). The most frequently used DNA sequences are ribosomal probes (45S rDNA and 5S rDNA) and telomeric probes (Weiss-Schneeweis et al., 2003). In some Asteraceae, such as Artemisia, FISH and chromosome banding techniques are of great taxonomic value. Torrel et al. (2003) did not support the taxonomic proposition of the separation of the subgenera Artemisia L. and Seriphidium (Besser ex W. Hook.) Poljakov as independent genera, due to similarity in the distribution pattern of $5 \mathrm{~S}$ rDNA loci.

Aiming to extend our knowledge of karyotype diversity in Vernonia, we applied different chromosome banding techniques, including AgNOR and triple staining with the fluorochromes CMA, DA (distamycin) and DAPI (CDD), and the FISH technique for the $45 \mathrm{~S}$ rDNA probe, in analyzing individuals of two populations of $V$. geminata.

\section{MATERIAL AND METHODS}

We analyzed the same populations of $V$. geminata studied by Oliveira et al. (2007a), collected in disturbed area, in Analândia, São Paulo State, Brazil. The population 1 occurred in an urban area and the population 2 in an open-pasture area, about $15 \mathrm{~km}$ away. Fruits, floral and vegetative branches of both populations were collected. Vouchers (population 1, VM Oliveira 44; population 2, VM Oliveira 82) were deposited in the herbarium of the Universidade Estadual de Campinas (UEC).

Root tips of newly germinated plants were pretreated with 0.002 M 8-hydroxyquinoline $(8 \mathrm{Hq})$ for $5 \mathrm{~h}$ at $14^{\circ}-15^{\circ} \mathrm{C}$. Afterwards, the root tips were fixed in Farmer solution (ethanol:acetic acid, 3:1, v/v) for $24 \mathrm{~h}$ and then transferred to $70 \%$ alcohol and stored in a freezer. For the preparation of samples with enzymatic digestion, the root tips were washed in distilled water and were dried with paper. The root tips were softened in an enzymatic solution containing $4 \%$ cellulase and $40 \%$ pectinase, in a moist chamber at $37^{\circ} \mathrm{C}$ for $2 \mathrm{~h}$. The squashing of the root tips between slides and coverslips was made in a drop of $45 \%$ acetic acid. The coverslips were removed in liquid nitrogen.

The slides were stored at room temperature for at least one day and then submitted to CDD and AgNOR banding. The CDD followed the protocol of Moscone et al. (1996). The slides were first stained with $0.5 \mathrm{mg} / \mathrm{mL} \mathrm{CMA}_{3}$ for $1 \mathrm{~h}$, and afterwards washed with distilled water. The slides were stained with $10 \mathrm{mg} / \mathrm{mL} \mathrm{DA}$ for $15 \mathrm{~min}$ and again washed with distilled water. Finally, they were stained with $2 \mathrm{mg} / \mathrm{mL}$ DAPI for $30 \mathrm{~min}$. The slides were again washed with distilled water and mounted with a solution containing Macllvaine buffer, $\mathrm{pH}$ 7.0 , and distilled water $(1: 1, \mathrm{v} / \mathrm{v})$ and $\mathrm{MgCl}_{2}$. The slides were stored in a dark box, at $37^{\circ} \mathrm{C}$ for 3 days, before being examined with an epifluorescence microscope. 
AgNOR banding followed the protocol of Moscone et al. (1995). The slides were washed in $0.01 \mathrm{M}$ borate buffer for $10 \mathrm{~min}$ and then with distilled water. Each slide received a drop of $50 \%$ silver nitrate and a piece of meshed nylon. The slides were stored at $60^{\circ} \mathrm{C}$ for $1 \mathrm{~h}$ and then washed in distilled water for $5 \mathrm{~min}$. The slides were mounted with Entellan.

The FISH was done according to Cuadrado and Jouve (1994), with the modifications of Fregonezi et al. (2004). The pTa71 probe (18S-5.8S-26rDNA) was labeled by nick translation (Bionick Gibco kit) with biotin-14dATP. Before hybridization, the spreads were pretreated with $1 \%$ RNase (1 RNase: $992 \mathrm{X} \mathrm{SSC}$ ), $\mathrm{pH} 7.0$, at $37^{\circ} \mathrm{C}$ for $1 \mathrm{~h}$, washed in $2 \mathrm{X}$ SSC, fixed in $4 \%$ paraformaldehyde, and again washed in $2 \mathrm{X}$ SSC. The slides were dehydrated in a 70 to $100 \%$ ethanol series and air-dried. Each slide was treated with labeling solution [ $100 \%$ formamide, $50 \%$ polyethylene glycol, $20 \mathrm{X} \mathrm{SSC}$, labeled probe (45S rDNA; 100-200 ng), salmon sperm and $10 \% \mathrm{SDS}$, denatured at $70^{\circ} \mathrm{C}$ and chilled on ice for $5 \mathrm{~min}$. Chromosomes were denatured and hybridized using a thermal cycler for $10 \mathrm{~min}$ at $90^{\circ} \mathrm{C}, 10$ min at $50^{\circ} \mathrm{C}, 10 \mathrm{~min}$ at $38^{\circ} \mathrm{C}$, and overnight at $37^{\circ} \mathrm{C}$ in a moist chamber. After hybridization, the slides were washed in $2 \mathrm{X} \mathrm{SSC}, 0.1 \mathrm{X} \mathrm{SSC}, 20 \%$ formamide, $0.1 \mathrm{X} \mathrm{SSC}, 2 \mathrm{X} \mathrm{SSC}$ and $4 \mathrm{X}$ $\mathrm{SSC} / 0.2 \%$ Tween 20 for $5 \mathrm{~min}$ at $42^{\circ} \mathrm{C}$ each. The signals were detected with avidin-FITC and the chromosomes were counterstained using propidium iodide.

The analysis of the slides was carried out with a light microscope (AgNOR banding) and an epifluorescence microscope (FISH and CDD banding). Photomicrographs of AgNOR banding were taken using black and white film, ISO 25. Photomicrographs of FISH were taken using black and white film, ISO 100, and Kodak ProImage color film, ISO 100, was used for FISH. In each slide, we examined at least 10 cells with adequate scattering and chromosome contraction. Oliveira et al. (2007a) previously reported ideograms of the same populations studied here. These authors used the conventional Giemsa staining and the classification and nomenclature of chromosomes suggested by Guerra (1988). In the present study, we used this ideogram to indicate the chromosome localization of CMA, DAPI and NOR bands, as well as small 45S rDNA sites.

\section{RESULTS}

The two populations of $V$. geminata analyzed showed $2 n=20$ and both possessed a pair of $\mathrm{CMA}^{+}$bands in the terminal region of the short arm of the fourth pair of submetacentric chromosomes (Figures 1 and 2). Neither showed bands with DAPI (neutral DAPI).

AgNOR banding demonstrated one pair of bands in both populations in the terminal region of the short arm of the fourth pair of submetacentric chromosome (Figure 1).

FISH showed in population 1 two pairs of $45 \mathrm{~S}$ rDNA sites, one small pair next to the centromeric region, in the short arm of the sixth pair of metacentric chromosomes, and another larger pair in the terminal region of the short arm of the fourth pair of submetacentric chromosomes. In population 2, we observed only one pair of small 45S rDNA sites, also situated in the terminal region of the short arm of the fourth pair of submetacentric chromosomes (Figures 1 and 2).

In some individuals of population 2 , besides the 20 chromosomes of the normal karyotype, there were $\mathrm{B}$ chromosomes, varying from 0 to 6 in different cells of the same individual $(2 \mathrm{n}=20+0-6 \mathrm{~B})$. In these B chromosomes, we could not see any CMA, DAPI or AgNOR bands, but one $45 \mathrm{~S}$ rDNA site was observed in two different chromosomes. 

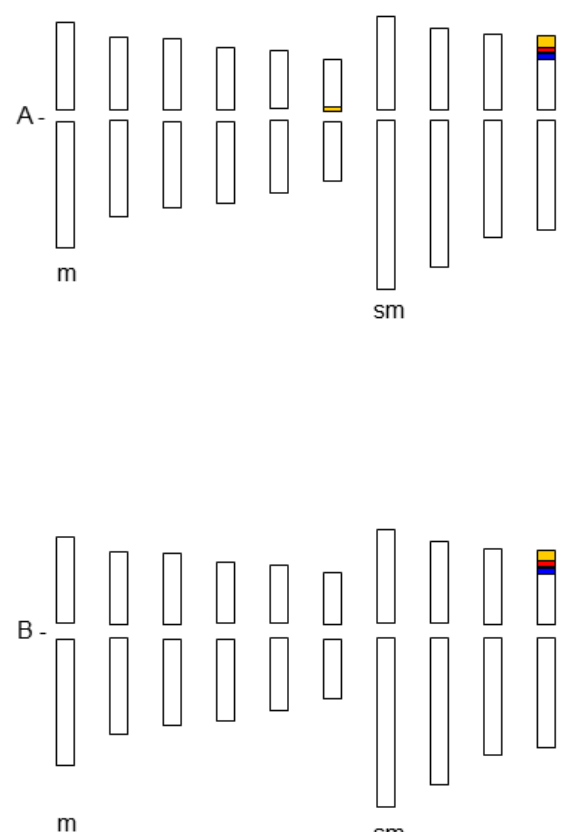

$\stackrel{1 \mu \mathrm{m}}{\longleftarrow}$

Figure 1. Ideograms of Vernonia geminata indicating the number and position of $\mathrm{CMA}^{+}$, $\mathrm{NOR}$ bands and number of $45 \mathrm{~S}$ rDNA sites. A. Population 1. B. Population 2. $\mathrm{m}=$ metacentric; $\mathrm{sm}=$ submetacentric.

\section{DISCUSSION}

According to Ruas et al. (1991), Dematteis (1996, 1998), Dematteis and Fernández $(1998,2000)$ and Oliveira et al. $(2007 a, b)$, despite the occurrence of variation in chromosome number among species of Vernonia, the karyotypes with conventional techniques do not discriminate well the species already studied, due to small variation in chromosome size and centromeric position. Among the species of Vernonia that belong to the group Axilliflorae Benth., studied by Oliveira et al. (2007a), V. geminata has the most differentiated karyotype, showing chromosomes with greater variation in length $(2.0$ to $4.6 \mu \mathrm{m})$ and greater proportion of submetacentric chromosomes, in relation to the metacentrics $(6 \mathrm{~m}+4 \mathrm{sm})$, where it is the only one with $2 \mathrm{n}=20$ chromosomes (pattern of the group is $\mathrm{x}=16$ ). Dysploidy can play a prominent role in the evolution of the species studied, as is the case for many species of Asteraceae. In species of Hypochaeris L., small structural alterations, such as translocations, and inversions involving loss and gain of chromosome fragments, sometimes containing the 45S rDNA region, are suggested to explain the dysploidy found in its karyotype evolution (WeissScheneeweiss et al., 2003).

There was coincidence between the AgNOR, $\mathrm{CMA}^{+}$and the small $45 \mathrm{~S}$ rDNA sites, only in one chromosome near the terminal region, in the short arm of the fourth submetacentric chromosome, in both populations (Figures 1 and 2). $\mathrm{CMA}^{+}$bands are not part of the $45 \mathrm{~S}$ rDNA sequence, but are arranged contiguously (Appels et al., 1998). Garnatje et al. (2004) 


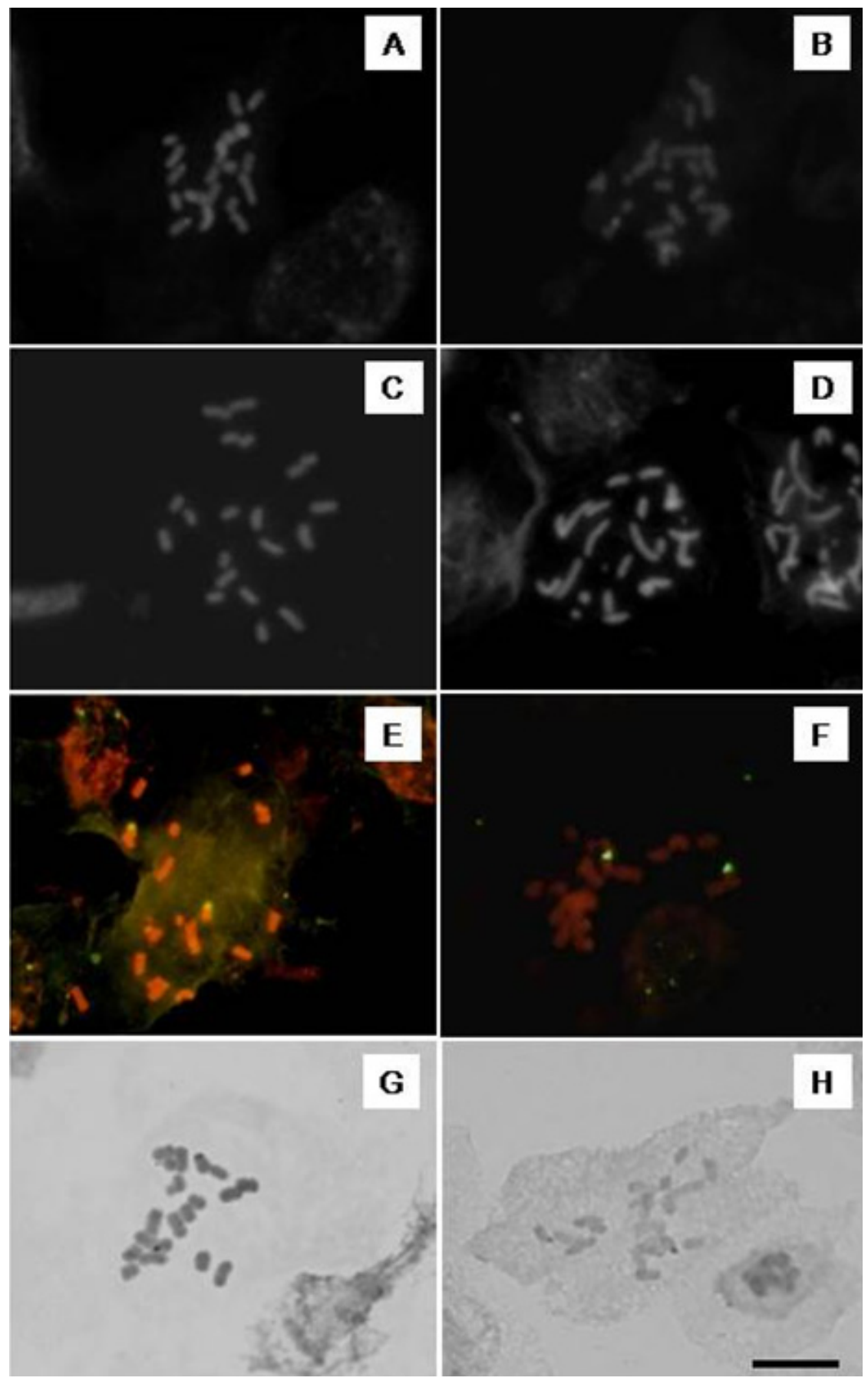

Figure 2. Metaphases of Vernonia geminata population $1(\mathbf{A}, \mathbf{C}, \mathbf{E}$, and $\mathbf{G})$ and population $2(\mathbf{B}, \mathbf{D}, \mathbf{F}$, and $\mathbf{H})$. A to $\mathrm{D}=\mathrm{CCD}$ banding $\left(\mathrm{A}\right.$ and $\mathrm{B}=\mathrm{CMA}_{3} / \mathrm{C}$ and $\left.\mathrm{D}=\mathrm{DAPI}\right) ; \mathrm{E}$ and $\mathrm{F}=\mathrm{FISH} ; \mathrm{G}$ and $\mathrm{H}=\mathrm{AgNOR}$ banding. $\mathrm{Bar}=10 \mu \mathrm{m}$. 
studied seven species of Xeranthemum L. and related genera belonging to the tribe Carduceae (Asteraceae), and observed that the $\mathrm{CMA}^{+}$bands and 45S rDNA sites, most of the time, share the same location, suggesting that repeat ribosomal sequences could be interspaced in heterochromatin.

The similar localization of AgNOR and CMA bands and 45S rDNA sites observed on the fourth submetacentric chromosome was not observed on the sixth metacentric chromosome of population 1. In this chromosome, only one 45S rDNA site was observed in the centromeric region of the short arm (Figures 1A and 2). Different numbers of 45S rDNA sites and $\mathrm{CMA}^{+}$ bands were previously observed in Cestrum L. (Fregonezi et al., 2004), Helianthus L. (Vanzela et al., 2002) and Crotalaria L. (Mondim et al., 2007). According to Mondim et al. (2007), in Crotalaria, $\mathrm{CMA}^{+}$bands could not be visualized due to the reduced size of its chromosomes.

In general, there is coincidence in the location of AgNOR and $\mathrm{CMA}^{+}$bands (Berger and Greilhuber, 1993). In accordance with Torrel et al. (2003), in Artemisia, small sites of rDNA are GC-rich and basically linked to the NORs. This exact pattern also occurs in other plants, such as Hypochaeris (Cerbah et al., 1995) and Dendranthema (DC.) Des Moul. (Kondo et al., 1996).

In the present study, we did not observe agreement between the number of $45 \mathrm{~S}$ rDNA sites and AgNOR bands. AgNOR banding only detects the active NORs that were transcribed during interphase proceeding cell division, while FISH shows the active and inactive regions (Murray et al., 1992).

In Vigna unguiculata (L.) Walp. (Galasso et al., 1995) and Lathyrus sativus L. (Murray et al., 1992), among the multiple small sites of 45S rDNA, only the largest was impregnated with silver ions, which was interpreted as inactivation of some NORs. Shi et al. (1996) also reported that in Glycine $\max$ (L.) Merr. and Phaseolus vulgaris L., not all signals of $5 \mathrm{~S}$ and 45S rDNA were associated with nucleoli during interphase.

The absence of small sites of $45 \mathrm{~S}$ rDNA and NOR/CMA ${ }^{+}$bands on the sixth metacentric chromosome of population 2 (Figure 1B) can indicate deletion of this sequence, present in population 1 (Figure 1A). However, it can be related to the reduced size of this sequence, as a result of small structural alterations, hindering the visualization of the small sites/bands. In Helianthus, small variations in the chromosomes had been detected, indicating in some cases, the loss or gain of rDNA regions, and these structural alterations could have an important role in the speciation of this genus (Vanzela et al., 2002). The results of the present study are still premature to conclude which mechanisms are involved in Vernonia. The FISH technique is more qualitative than quantitative, but an association between the size of the FISH sites and the number of repeated sequences of rDNA can be demonstrated, and thus, more intense signals represent small sites with a larger number of repeated sequences of less intense signals (Fregonezi et al., 2004).

Lima-de Faria (1976) suggested that 45S rDNA sites in short arm of chromosomes are a general trend within the Asteraceae. Studies involving FISH of 45S rDNA in species of this family have also shown this trend (Vanzela et al., 2002; Torrel et al., 2003; Garnatje et al., 2004; Fregonezi et al., 2004).

In population 2 , the occurrence of up to six chromosomes $(2 n=20+0-6 B)$ was previously observed by Oliveira et al. (2007a) in the same population. These extra-chromosomes occur in some species of Vernonia (Dematteis, 1997, 1998) and other Asteraceae, such as Mikania Willd. (Maffei et al., 1999), Crepis capillaris (L.) Wallr. (Whitehouse et al., 1981) and Calycadenia pauciflora A. Gray (Carr and Carr, 1982). The observation of 45S rDNA sites 
in two B chromosomes of $V$. geminata (Figure 2F) was not coincident with fluorescent and AgNOR bands. Thus, these sites must be inactive NOR (Murray et al., 1992). The presence of $45 \mathrm{~S}$ rDNA sites in B chromosomes was previously reported in other Asteraceae such as $C$. capillaris (Jamilena et al., 1994) and Brachycome dichromosomatica C.R. Carter (Marschner et al., 2007).

There is no published data based on the FISH technique in other species of Vernonia, and fluorochrome staining with CMA/DAPI was reported only for $V$. condensata (Salles-deMelo et al., 2010), which revealed five chromosome pairs bearing subterminal $\mathrm{CMA}^{+} / \mathrm{DAPI}^{-}$ heterochromatin. We observed here in two populations of $V$. geminata only one chromosome pair bearing terminal $\mathrm{CMA}^{+} / \mathrm{DAPI}-$ heterochromatin. However, $V$. geminata and $V$. condensata have different chromosome numbers and belong to different sections, Lepidaploa (Cass.) DC. and Orbisvestus S.B. Jones, respectively (Baker, 1873).

There appears to be substantial intraspecific variation in $V$. geminata, in view of the different possible numbers of $45 \mathrm{~S}$ rDNA sites in B chromosomes and next to the centromeric region, in the short arm of the sixth pair of metacentric chromosomes. According to Vanzela et al. (2002), loss or gain of rDNA regions plays an important role in speciation in the genus Helianthus. Complementary chromosome studies in V. geminata and other species of Vernonia would contribute to our knowledge of the evolution and taxonomy of this group of plants.

\section{ACKNOWLEDGMENTS}

Research supported by Fundação de Amparo à Pesquisa do Estado de São Paulo (FAPESP; Grant \#04/13165-9). V.M. Oliveira was awarded a scholarship from FAPESP and E.R. Forni-Martins a research fellowship from Conselho Nacional de Desenvolvimento Científico e Tecnológico (CNPq).

\section{REFERENCES}

Appels R, Moris R, Gill S and May C (1998). Chromosome Biology. Kluwer, Boston.

Baker JG (1973). Compositae I. Vernonieae. In: Flora Brasiliensis (Martius CF and Eichler AG, eds.). Monachii, Lipsiae, 1-180.

Berger C and Greilhuber J (1993). Cold-sensitive chromosome regions and heterochromatin in Cestrum (Solanaceae): $C$. strigillatum, C. fasciculatum, and C. elegans. Plant Syst. Evol. 185: 133-151.

Carr GD and Carr RL (1982). Micro and nucleolar-organizing B-chromosomes in Calycadenia (Asteraceae). Cytologia 47: 79-87.

Cerbah M, Coulaud J, Godelle B and Siljak-Yakovlev S (1995). Genome size, fluorochrome banding, and karyotype evolution in some Hypochoeris species. Genome 38: 689-695.

Cuadrado A and Jouve N (1994). Mapping and organization of highly-repeated DNA sequences by means of simultaneous and sequential FISH and C-banding in 6x-triticale. Chromosome Res. 2: 331-338.

Dematteis M (1996). Estudios cromosómicos en especies argentinas de Vernonia (Asteraceae). Bonplantia 9: 103-110.

Dematteis M (1997). Números cromosómicos y cariotipos en algunas espécies de Vernonia (Asteraceae). Bol. Soc. Argent. Bot. 33: 85-90.

Dematteis M (1998). Chromosome studies of some Vernonia species (Asteraceae). Genet. Mol. Biol. 21: 381-385.

Dematteis M and Fernández A (1998). Karyotypes of seven South American species of Vernonia (Asteraceae). Cytologia 63: 323-328.

Dematteis M and Fernández A (2000). Chromosome studies on nine South American species of Vernonia (Vernonieae, Asteraceae). Caryologia 53: 55-61.

Fregonezi JN, Torezan JMD and Vanzela ALL (2004). A karyotypic study of three southern Brazilian Asteraceae species using fluorescence in situ hybridization with a 45S rDNA probe and C-CMA3 banding. Genet. Mol. Biol. 27: 223-227.

Galasso I, Schmidt T, Pignone D and Heslop-Harrison JS (1995). The molecular cytogenetics of Vigna unguiculata (L.) 
Walp: the physical organization and characterization of 18S-5.8S-25S rRNA genes, 5S rRNA genes, telomere-like sequences, and a family of centromeric repetitive DNA sequences. Theor. Appl. Genet. 91: 928-935.

Garnatje T, Valles J, Vilatersana R, Garcia-Jacas N, et al. (2004). Molecular cytogenetics of Xeranthemum L. and related genera (Asteraceae, Cardueae). Plant Biol. 6: 140-146.

Goodpasture C and Bloom SE (1975). Visualization of nucleolar organizer regions im mammalian chromosomes using silver staining. Chromosoma 53: 37-50.

Guerra M (1988). Introdução à Citogenética Geral. Editora Guanabara, Rio de Janeiro.

Guerra M, Dos Santos KG, Barros E Silva AE and Ehrendorfer F (2000). Heterochromatin banding patterns in RutaceaeAurantioideae - a case of parallel chromosomal evolution. Am. J. Bot. 87: 735-747.

Jamilena M, Ruiz RC and Ruiz RM (1994). A molecular analysis of the origin of the Crepis capillaris B chromosome. $J$. Cell Sci. 107 (Pt 3): 703-708.

Jorgensen PM and Ulloa CU (1994). Seed plants of the high Andes of Ecuador: a checklist. AAU Reports 34: 1-443.

Kondo K, Honda Y and Tanaka R (1996). Chromosome marking in Dendranthema japonica var. wakasaense and its closely related species by fluorescence in situ hybridization using rDNA probe. Kromosomo II-81: 2785-2791.

Leitch AR, Schwarzacher T, Jackson D and Leitch IJ (1994). In Situ Hybridization. BIOS Scientific Publishers Ltd., Oxford.

Lima-de Faria A (1976). The chromosome field I. Prediction of the localization of ribosomal cistrons. Hereditas 83: 1-22.

Maffei EMD, Marin-Morales MA, Ruas PM and Ruas CF (1999). Chromosomal polymorphism in 12 populations of Mikania micrantha (Compositae). Genet. Mol. Biol. 22: 433-444.

Marschner S, Meister A, Blattner FR and Houben A (2007). Evolution and function of B chromosome 45S rDNA sequences in Brachycome dichromosomatica. Genome 50: 638-644.

Martínez-Hernández E, Cuadriello-Aguilar JI, Ramírez Arriaga E, Medina Camacho M, et al. (1994). Foraging of Nannotrigona testaceicornis, Tetragona jaty, Scaptotrigona pachysoma and Plebeia sp. at Tacana región, Chiapas, México. Grana 33: 205-217.

Mondin M, Santos-Serejo JA and Aguiar-Perecin MLR (2007). Karyotype characterization of Crotalaria juncea (L.) by chromosome banding and physical mapping of 18S-5.8S-26S and 5S rRNA gene sites. Genet. Mol. Biol. 30: 65-72.

Moscone EA, Loidl J, Ehrendorfer F and Hunziker AT (1995). Analysis of active nucleolus organizing regions in Capsicum (Solanaceae) by silver staining. Am. J. Bot. 82: 276-287.

Moscone EA, Lambrou M and Ehrendorfer F (1996). Fluorescent chromosome banding in the cultivated species of Capsicum (Solanaceae). Plant Syst. Evol. 202: 37-63.

Murray BG, Bennett MD and Hanmet RW (1992). Secondary constrictions and NORs of Lathyrus investigated by silver staining and in situ hybridization. Heredity 68: 473-478.

Oliveira VM, Forni-Martins ER and Semir J (2007a). Cytotaxonomy of species of Vernonia, section Lepidaploa, group Axilliflorae (Asteraceae, Vernonieae). Bot. J. Linn. Soc. 154: 99-108.

Oliveira VM, Forni-Martins ER and Semir J (2007b). Cytotaxonomic studies in six species of Vernonia (Asteraceae: Vernonieae). Caryologia 60: 37-47.

Robinson H (1999). Generic and subtribal classification of American Vernonieae. Smith. Contr. Bot. 89: 1-116.

Ruas PM, Ruas CF, Vieira AOS, Matzenbacher N, et al. (1991). Cytogenetics of genus Vernonia Schreber (Compositae). Cytologia 56: 239-247.

Sales-de-Mello MRC, de Lucena RM, Semir J, de Carvalho R, et al. (2010). Karyological features and cytotaxonomy of the tribe Vernonieae (Asteraceae). Plant Syst. Evol. 285: 189-199.

Schweizer D (1976). Reverse fluorescent chromosome banding with chromomycin and DAPI. Chromosoma 58: 307-324.

Shi L, Zhu T and Kein P (1996). Ribosomal RNA genes in soybean and common bean: chromosomal organization, expression, and evolution. Theor. Appl. Genet. 93: 136-141.

Stutts JG (1988). Taxonomic revision of Vernonieae Subsect. Chamaedrys (Compositae: Vernonieae). Rhodora 90: 37-99.

Torrell M, Cerbah M, Siljak-Yakovlev S and Vallès J (2003). Molecular cytogenetics of the genus Artemisia (Asteraceae, Anthemideae): fluorochrome banding and fluorescence in situ hybridization. I. Subgenus Seriphidium and related taxa. Plant Syst. Evol. 239: 141-153.

Vanzela ALL, Ruas CF, Oliveira MF and Ruas PM (2002). Characterization of diploid, tetraploid and hexaploid Helianthus species by chromosome banding and FISH with 45S eDNA probe. Genetica 114: 105-111.

Weiss-Schneeweiss H, Stuessy T, Siljak-Yakovlev S, Baeza C, et al. (2003). Systematic and evolutionary implications of karyotypes of Hypochaeris (Asteraceae, Lactuceae) from South America. Plant Syst. Evol. 241: 171-184.

Whitehouse C, Edgar LA, Jones GH and Parker JS (1981). The population cytogenetics of Crepis capillaris I. Chiasma variation. Heredity 47: 95-103. 